Pacific Journal of Mathematics

EVERY ABELIAN GROUP IS A CLASS GROUP 


\title{
EVERY ABELIAN GROUP IS A CLASS GROUP
}

\author{
LUTHER CLABORN
}

Let $T$ be the set of minimal primes of a Krull domain $A$. If $S$ is a subset of $T$, we form $B=\cap A_{P}$ for $P \in S$ and study the relation of the class group of $B$ to that of $A$. We find that the class group of $B$ is always a homomorphic image of that of $A$. We use this type of construction to obtain a Krull domain with specified class group and then alter such a Krull domain to obtain a Dedekind domain with the same class group.

Let $A$ be a Krull domain with quotient field $K$. Thus $A$ is an intersection of rank 1 discrete valuation rings; and if $x \in K, x$ is a unit in all but a finite number of these valuation rings. If $P$ is a minimal prime ideal of $A$, then $A_{P}$ is a rank 1 discrete valuation ring and must occur in any intersection displaying $A$ as a Krull domain. In fact, if $T$ denotes the set of minimal prime ideals of $A$, then $A=\bigcap_{P \in T} A_{P}$ displays $A$ as a Krull domain.

Choose a subset $S$ of $T(S \neq \varnothing)$ and form the domain $B=$ $\bigcap_{P \in S} A_{p}$. It is immediate that $B$ is also a Krull domain which contains $A$ and has quotient field $K$. If one of the $A_{P}$ were eliminable from the intersection representing $B$, it would also be eliminable from that representing $A$. Thus the $A_{P}$ for $P \in S$ are exactly the rings of the type $B_{Q}$, where $Q$ is a minimal prime ideal of $B$. If $Q$ is minimal prime ideal of $B$, then $Q \cap A=P$ for the $P \in S$ such that $B_{Q}=A_{P}$.

Let $A$ and $B$ be generic labels throughout this paper for a Krull domain $A$ and a Krull domain $B$ formed from $A$ as above. We recall that the valuation rings $A_{P}$ are called the essential valuation rings, and we will denote by $V_{P}$ the valuation of $A$ going with $A_{P}$. We summarize and add a complement to the above.

Proposition 1. With $A$ and $B$ as above, $B$ is a Krull domain containing $A$, and the $A_{P}$ for $P \in S$ are the essential valuation rings of $B$. Every ring $B$ is of the form $A_{M}$ for some multiplicative set $M$ if and only if the class group of $A$ is torsion.

Proof. Everything in the first assertion has been given above.

Suppose the class group of $A$ is torsion; then for each $Q_{i}$ in $T-$ $S$ choose an integer $n_{i}$ such that $Q_{i}^{\left(n_{i}\right)}$ is principal, say $Q_{i}^{\left(n_{i}\right)}=A s_{i}$. Let $M$ be the multiplicative set generated by all $s_{i}$. Then [3, 33.5, 
p. 116] shows that $B=A_{M}$. On the other hand, if $Q$ is a prime ideal of $A$ whose class is not torsion, then the same reference shows that $B=\bigcap_{P \neq Q} A_{P}$ cannot be of the form $A_{M}$.

Let $C(A)$ denote the class group of $A$ for any Krull domain $A$. Samuel [4] has shown how to define a homomorphism of $C(A)$ into $C(B)$ when $B$ is a Krull domain such that $A \subseteq B$ and $B$ is $A$-flat. Of course, our rings $B$ are not necessarily $A$-flat, but we have nonetheless:

Proposition 2. $C(B)$ is a homomorphic image of $C(A)$.

Proof. Let $I$ be an ideal of $A$ defined by essential valuation conditions. Although $I B$ may not be defined by essential valuation: conditions, $B:(B: I B)$ is and is quasi-equal to $I B$ [5, p. 92]. If $P(A)$ and $P(B)$ denote the ideals of $A$ and $B$ defined by essential valuation conditions, let $g: P(A) \rightarrow P(B)$ be defined by $g(I)=B:(B: I B)$. It is easy to see that if $I$ is the ideal $\left\{x: V_{P}(x) \geqq n_{P} ; P \in T\right\}$, then $g(I)$ is the ideal $\left\{x: V_{P}(x) \geqq n_{P}, P \in S\right\}$. Since the product $I \circ I^{\prime}$ (see [4]) is $A:\left(A: I I^{\prime}\right)$, the above description yields immediately that $g\left(I \circ I^{\prime}\right)=$ $g(I)^{0} g\left(I^{\prime}\right)$. If $x \in A$, then $g(x A)=B:(B: x B)=x B$, so $g$ induces a homomorphism $\bar{g}: C(A) \rightarrow C(B)$ which is obviously onto.

CoROLlary 3. With $\bar{g}$ as defined in Proposition 2, the kernel of $\bar{g}$ is the subgroup of $C(A)$ generated by all minimal primes $Q$ of $A$ for which $Q \notin S$.

Proof. If $Q \notin S$, then $g(Q)=B$. If on the other hand $g(I)$ is. principal, we have $g(I)=x B$ or $g\left(x^{-1} I\right)=B$. Thus $x^{-1} I$ is in the subgroup of $P(A)$ generated by certain $Q \notin S$.

In the next two propositions, we generalize to Krull domains. certain results of [1] and [2].

Proposition 4. If $A$ is a Krull domain, then $A[X]$ is a Krull domain. $C(A)$ is isomorphic to $C(A[X])$, and every class of $C(A[X])$, contains a prime ideal of $A[X]$.

Proof. Everything but the last assertion is [4, Prop. 3., p. 158]. Let $c$ be an element of $C(A[X])$; then $c^{-1}$ can be represented by $I A[X]$, where $I$ is an integral ideal of $A$ defined by essential valuation conditions. Choose $a_{0}$ and $a_{1}$ in $A$ so that $I$ is quasi-equal to $\left(a_{0}, a_{1}\right)$ [5, Exer. 4., p. 95]. Consider the prime ideal $P=\left(a_{0}+a_{1} X\right) K[X] \cap A[X]$. It is clear that $P=I^{-1} A[X] \cdot\left(a_{0}+a_{1} X\right) A[X][6$, p. 85]. So $P$ is in $c$. 
Proposition 5. If $G$ is the class group of a Krull domain and $G^{\prime}$ is a homomorphic image of $G$, then there is a Krull domain with class group $G^{\prime}$.

Proof. Let $A$ have class group $G$ and let $H$ be a subgroup of $G$ such that $G^{\prime} \cong G / H . \quad G$ is also the class group of $A[X]$; choose (Proposition 4) a minimal prime $P_{\alpha}$ of $A[X]$ representing each class $\boldsymbol{c}_{\alpha}$ in $H$. Let $T$ be the set of all minimal primes of $A[X]$ and let $U$ be the set of primes $\left\{P_{\alpha}\right\}$. Then $B=\bigcap_{P \in K^{\prime}-U} A[X]_{P}$ has class group $G^{\prime}$ by Corollary 3 .

Proposition 6. If $G$ is any abelian group, then there is a Krull domain $A$ such that $C(A) \cong G$.

Proof. In view of Proposition 5, it is sufficient to show that there is a Krull domain whose class group is a free group on a base of given cardinality. We do so as follows:

Let $J$ be any index set and form the polynomial ring $B=$ $F\left[X_{1}, Y_{1}, Z_{1}, \cdots, X_{i}, Y_{i}, Z_{i}, \cdots\right]$ for $i \in J$. For each $i$, consider the subring $R_{i}=F\left[\cdots, X_{i}, Y_{i}, W_{i}, \cdots,\right]$ where $W_{i}=X_{i} Z_{i}$. Let $Q_{i}$ be the ideal $\left(X_{i}, Y_{i}\right)$ in $R_{i}$ and assign an order to any element $r$ of $R_{i}$ by $v_{i}(r)=t$ if $r \in Q^{t}$ and $r \notin Q^{t+1}$. It is immediate that $v_{i}$ satisfies the requirements of a valuation, and so $v_{i}$ may be extended uniquely to a discrete valuation on the quotient field of $R_{i}$ (= the quotient field of $B$ ).

Let $V_{i}$ denote the valuation ring of $v_{i}$ for all $i \in J$. Form $A=$ $\left(\bigcap_{i \in J} V_{i}\right) \cap B$. We assert that $A$ is a Krull domain, and that $C(A)$ is the free group on $J$.

We note first that since $A \supseteqq R_{i}$ for any $i \in J$, the quotient field of $A$ is the same as the quotient field of $B$. Since $B$ is a U.F.D., we can write $B=\cap B_{P}$ for $P$ a minimal prime of $B$; this shows that $A$ is the intersection of discrete valuation rings. If $f \in A, f$ involves only a finite number of the variables, and so $f$ can be a nonunit in only a finite number of the $\left\{B_{P}\right\} \cup\left\{V_{i}\right\}$. The set $\Sigma=\left\{B_{P}\right\} \cup\left\{V_{i}\right\}$ is in fact, the set of essential valuation rings of $A$. To see this, we need only produce an element of the quotient field which is not in a particular ring of $\Sigma$ but is in all the other rings of $\Sigma$. For $V_{i}, Z_{i}$ will serve. If $P$ is a minimal prime of $B$ and $P=X_{i} B$ for some $i \in J$, $Y_{i} / X_{i}$ demonstrates that $B_{P}$ is essential.

Finally, let $P$ be a minimal prime of $B$ not of the above type and choose an $f \in B$ such that $P=f B$. $f$ will be a unit in any other valuation ring of $\Sigma$ of the type $B_{Q}$, so let $V_{i_{1}}, \cdots, V_{i_{k}}$ be the valuation rings of $\Sigma$ in which $f$ is not a unit. Let $n_{i_{j}}=v_{i_{j}}(f)$ for $j=$ $1, \cdots, k$. The element $g=X_{i_{1}}^{\max \left(0, n_{i_{1}}\right)} \cdots X_{i_{k}}^{\max \left(0, n_{i k}\right)} / f$ yields that $B_{P}$ is essential in this case. 
Let $P$ be a minimal prime of $B$, and choose $f \in B$ such that $P=$ $f B$. As above, $f$ is a unit except in $B_{P}$ and some rings $V_{i}$ for $i \in J$. This shows that the minimal primes going with the $V_{i}$ generate $C(A)$. A relation among these minimal primes alone would come from an element $f$ of the quotient field of $A$ which is a unit in all $B_{P}$, i.e., a unit of $B$. But the units of $B$ are the elements of the field $F$, and this relation can only be the trivial one.

REMARK. It is fairly easy to see that the restriction of the ring $A$ constructed above to $F\left[X_{i}, Y_{i}, Z_{i}\right]$ is $F\left[X_{i}, Y_{i}, X_{i} Z_{i}, Y_{i} Z_{i}\right]$; this leads to an alternative description of $A$ as $F\left[\cdots, X_{i}, Y_{i}, T_{i}, U_{i} \cdots\right]$ subject to the relations $X_{i} U_{i}=Y_{i} T_{i}$. Indeed, the results on $A$ may be obtained by viewing $A$ again as a subring of $F\left[\cdots, X_{i}, Y_{i}, Z_{i}, \cdots\right]$ where $Z_{i}=T_{i} / X_{i}=U_{i} / Y_{i}$. I am indebted to the referee for suggesting this point of view on the example.

THEOREM 7. Given any abelian group $S$, there is a Dedekind domain $D$ with $C(D) \cong S$.

Proof. We show that if $A$ is a Krull domain with class group $S$, we can alter $A$ to obtain a Dedekind domain with the same class group.

Let $N$ denote the natural numbers and set $A_{1}=A\left[X_{1}, \cdots, X_{n}, \cdots\right]$ for $n \in N$. Let $Q$ be a prime ideal of $A$, which is not minimal. Choose any element $a$ of $Q$ and let $P_{1}, \cdots, P_{k}$ be the minimal primes of $A_{1}$ which contain $a$. Since $Q \nsubseteq P_{1} \cup \cdots \cup P_{k}$ we can find $b$ in $Q$ such that $b \notin P_{i}$ for $i=1, \cdots, k$. Let $X_{Q}$ be a variable not occuring in either $a$ or $b$ and form $f_{Q}=a+b X_{Q}$. Then $f_{Q}$ is prime in $A_{1}$ [6, Th. 29, p. 85]. Let $M$ be the multiplicative set generated by all $f_{Q}$, where $Q$ ranges over the nonminimal primes of $A_{1}$. Let $D=\left(A_{1}\right)_{M}$. $D$ is a Krull domain in which minimal primes are also maximal, so $D$ is a Dedekind domain [6, Th. 28, p. 84]. Further $C(A) \cong C\left(A_{1}\right) \cong C(D)$, the latter isomorphism following from [4, Prop. 2, p. 157].

\section{REFERENCES}

1. L. Claborn, Dedekind domains and rings of quotients, Pacific J. Math. 15 (1965), 59-64.

2. - Dedekind domains: overrings and semi-prime elements, Pacific J. Math. 15 (1945), 799-804.

3. M. Nagata, Local Rings, Interscience, New York, (1962).

4. P. Samuel, Sur les anneaux factoriels, Bull. Soc. Math. France, 89 (1961), 155-173.

5. B. Van der Waerden, Modern Algebra, Vol. II, Julius Springer Berlin, (1940).

6. O. Zariski and P. Samuel, Commutative Algebra, Vol. II, D. Van Nostrand Company, Princeton, (1960).

Received January 27, 1965, and in revised form April 10, 1965. 


\section{PACIFIC JOURNAL OF MATHEMATICS}

\section{EDITORS}

H. SAMELSON

Stanford University

Stanford, California

R. M. BLUMENTHAL

University of Washington

Seattle, Washington 98105

\section{*J. DugundJI}

University of Southern California Los Angeles, California 90007

RICHARD ARENS

University of California

Los Angeles, California 90024

\section{ASSOCIATE EDITORS}

E. F. BECKENBACH
F. WOLF

K. YosIDA

\section{SUPPORTING INSTITUTIONS}

\author{
UNIVERSITY OF BRITISH COLUMBIA \\ CALIFORNIA INSTITUTE OF TECHNOLOGY \\ UNIVERSITY OF CALIFORNIA \\ MONTANA STATE UNIVERSITY \\ UNIVERSITY OF NEVADA \\ NEW MEXICO STATE UNIVERSITY \\ OREGON STATE UNIVERSITY \\ UNIVERSITY OF OREGON \\ OSAKA UNIVERSITY \\ UNIVERSITY OF SOUTHERN CALIFORNIA
}

\author{
STANFORD UNIVERSITY \\ UNIVERSITY OF TOKYO \\ UNIVERSITY OF UTAH \\ WASHINGTON STATE UNIVERSITY \\ UNIVERSITY OF WASHINGTON \\ AMERICAN MATHEMATICAL SOCIETY \\ CHEVRON RESEARCH CORPORATION \\ TRW SYSTEMS \\ NAVAL ORDNANCE TEST STATION
}

Mathematical papers intended for publication in the Pacific Journal of Mathematics should be typewritten (double spaced). The first paragraph or two must be capable of being used separately as a synopsis of the entire paper. It should not contain references to the bibliography. Manuscripts may be sent to any one of the four editors. All other communications to the editors should be addressed to the managing editor, Richard Arens at the University of California, Los Angeles, California 90024 .

50 reprints per author of each article are furnished free of charge; additional copies may be obtained at cost in multiples of 50 .

The Pacific Journal of Mathematics is published monthly. Effective with Volume 16 the price per volume (3 numbers) is $\$ 8.00$; single issues, $\$ 3.00$. Special price for current issues to individual faculty members of supporting institutions and to individual members of the American Mathematical Society: $\$ 4.00$ per volume; single issues $\$ 1.50$. Back numbers are available.

Subscriptions, orders for back numbers, and changes of address should be sent to Pacific Journal of Mathematics, 103 Highland Boulevard, Berkeley 8, California.

Printed at Kokusai Bunken Insatsusha (International Academic Printing Co., Ltd.), No. 6, 2-chome, Fujimi-cho, Chiyoda-ku, Tokyo, Japan.

PUBLISHED BY PACIFIC JOURNAL OF MATHEMATICS, A NON-PROFIT CORPORATION

The Supporting Institutions listed above contribute to the cost of publication of this Journal, but they are not owners or publishers and have no responsibility for its content or policies.

* Paul A. White, Acting Editor until J. Dugundji returns. 


\section{Pacific Journal of Mathematics}

\section{Vol. 18, No. 2 \\ April, 1966}

Alexander V. Arhangelskii, On closed mappings, bicompact spaces, and a problem of P. Aleksandrov .............................. 201

A. K. Austin, A note on loops . . . . . . . . . . . . . . . . . . . . . . . . . . . . 209

Lawrence Peter Belluce and William A. Kirk, Fixed-point theorems for families of contraction mappings...................... 213

Luther Elic Claborn, Every abelian group is a class group ............ 219

Luther Elic Claborn, A note on the class group .................. 223

Robert Stephen De Zur, Point-determining homomorphisms on multiplicative semi-groups of continuous functions............. 227

Raymond William Freese, A convexity property ................ 237

Frederick Paul Greenleaf, Characterization of group algebras in terms of their translation operators ......................... 243

Andrzej Hulanicki, On the spectral radius of hermitian elements in group algebras....................................... 277

Michael Bahir Maschler and Bezalel Peleg, A characterization, existence proof and dimension bounds for the kernel of a game ............ 289

Yiannis (John) Nicolas Moschovakis, Many-one degrees of the predicates

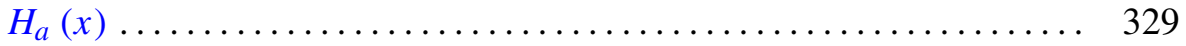

G. O. Okikiolu, $n$th order integral operators associated with Hilbert transforms.

C. E. Rickart, Analytic phenomena in general function algebras ... 361

K. N. Srivastava, On an entire function of an entire function defined by Dirichlet series

Paul Elvis Waltman, Oscillation criteria for third order nonlinear differential equations .......................... 